\title{
Effects of Action Learning-based Pediatric Nursing Practice Education Program on Problem Solving Abilities, Competency in Nursing Skills, Self-efficacy for Group Work, and Team Efficacy of Nursing College Students
}

\author{
Seok-Young Han \\ Department of Nursing Science, Chosun Nursing College, Philmundaero, Dong-gu, \\ Gwangju, 61453, South Korea \\ hansy4ever@cnc.ac.kr
}

\begin{abstract}
This study was conducted to examine effects of action learning-based pediatric nursing practice education (AL-PNPE) program for nursing students. A quasi-experimental study with a non-equivalent control group pretest-posttest design was used. The study participants were 82 nursing students (42 in the experimental group and 40 in the control group) from $G$ metropolitan city in South Korea. The experimental group took part in the AL-PNPE program, which was scheduled to take place twice per week for 10 days, while the control group took part in a traditional pediatric nursing practice education course. The data were analyzed using descriptive statistics, $\chi^{2}$-test, ANCOVA, and an independent t-test using SPSS/WIN 22.0. There were significant increases in problem solving abilities $(t=4.49, p<.001)$, competency in nursing skills $(t=3.99, p<.001)$, self-efficacy for group work $(t=3.91, p<.001)$, and team efficacy $(t=2.25, p=.027)$ in the experimental group compared to the control group. Based on the findings, this study indicates that AL-PNPE is an effective teaching-learning method to improve problem solving abilities, competency in nursing skills, self-efficacy for group work, and team efficacy of nursing college students. Therefore, Repetitive researches on action learning based education programs for nursing students are demanded, as is a cross-sectional research to verify the effects after providing direct action learning during pediatrics nursing clinical practice.
\end{abstract}

Keywords: Action learning, Clinical competence, Problem-solving, Self-efficacy, Team efficacy

\section{Introduction}

In the era of the 4th industrial revolution, it is greatly required not only to be capable of 'learn to learn' self-initiative learning but also to have problem-solving ability of creating something new by forming a team with a number of people, as well as to have an ability to cooperate through communication [1]. That is, the concept of a competent person in the future society is a person who can apply his/her own knowledge to solve problems and can serve his role and function as a constituent of a team, rather than a person who simply possesses knowledge [2]. For this reason, the universities, in order to train people that show competency required in a future society, should seek a way of learning that offers learners opportunities for problem

Article history:

Received (January 18, 2021), Review Result (February 20, 2021), Accepted (March 31, 2021) 
solving and cooperation. To achieve this desirable future-oriented education, it is the nursing professors' duty to provide a surrounding that enables learners to learn their skills that could be utilized in clinical practice focused on the present and future, and, in turn, it is the learners' duty to cooperate in a group-centered way through initiative collaboration and discussion. This will lead to a formation of a learning environment centered on effective challenges that will enhance learners' core abilities [3]. Therefore, an emphasis is laid on the context of actual learning, learning experience, cooperative learning, working out a solution of a problem with a fellow learner, and the shift in role of professors as a promoter of learning process [4].

The design and theory for a learner-centered education includes problem-centered learning, achievement-centered scenario, situation studies, and action learning. The common point that is shared by these designs and theories is the fact that learning takes place in the course of solving assignments of an actual context. Especially, action learning sets itself apart from other designs on the point that learning takes place in the course of solving real assignments [5]. Action learning is a method of developing oneself intellectually, sensitively and collaboratively by participating in an assignment that is actual, complex and straining so as to make an intentional change to improve his/her behavior in an assigned situation. In addition, action learning pays great attention to learner-centered education which enables learners to learn during the process of eager participation as well as diverse experiences. On top of that, the fact that action learning is a teaching-learning method in which collaborative clinical practice and learning takes place at once has led to nursing educators attempting multidisciplinary approach when developing learner centered curriculums and pedagogics [6][7][8], it has also been introduced to nursing education as a teaching-learning method where its efficiency is currently being evaluated [9].

The environment surrounding clinical nursing practice has changed so rapidly that it is not only required to learn the fundamental professional knowledge but also to view his/her duty and organization differently as a consequence of reflection on new clinical nursing practice issues, as well as of cultivation of problem-solving capabilities [10]. Action learning must take place through team activity that ensures learners balanced handling of assignment and learning, new perspectives in observing assignments and applying them to clinical nursing practice, reflective thinking on the application, and a wider vision and deeper thoughts. Furthermore, a successful cooperative clinical assignment completed as a group improves the learners' selfefficacy which in turn promotes the demonstration of nursing core competency through an organized collaborative effort [11]. Especially, in the case of nursing students, since they understand and analyze the actual surroundings of the field of nursing through understanding the flow of various nursing duties and interventions by applying nursing knowledge previously acquired during clinical practice, team-based action learning - which fosters creative problemsolving abilities and team cooperation - could be facilitated effectively to achieve outcomes during pediatric nursing practice education courses [12][13].

Core fundamental nursing skill, which should be attained during pediatric nursing practice education course, is an essential element for the solution of patients' health problems in clinical nursing fields [14], and a variety of teaching-learning methods has been introduced to teach effective essential nursing skills effectively. Despite the fact that teaching methods known to be effective such as self-initiated clinical nursing practice, simulation using a standardized patient, web-based learning have been applied to nursing skill education [15][16], it is problematic for a nursing college student to spend sufficient time participating in such methods on his/her own initiative.

Hence a number of studies researching a learning method that uses smart phones which show a video of a performance of core fundamental nursing skill for self-evaluation as well as peer 
evaluation, has steadily taken place; they report that the aforementioned method keeps the positive reinforcement of nursing college students, which consequently improves self-initiative and the accomplishment of core fundamental nursing skills [17]. Particularly, filming videos showing core fundamental nursing skills will induce nursing college students - who are familiar with smart phones - an incentive to learn; it is likely to improve their ability to perform nursing skills.

Therefore, this study aims to develop AL-PNPE program for nursing students and verify effects the program has on nursing students' abilities to solve problems and to perform nursing skills, as well as effects on cooperative self-efficacy and team efficacy.

The hypotheses for the purpose of this study are as follows.

Hypothesis 1. In the survey that examines problem-solving abilities, the experimental group who participated in AL-PNPE program will show a different mark compared to the control group. Hypothesis 2 . In the survey that examines nursing skill performance, the experimental group who participated in AL-PNPE program will show a different mark compared to the control group. Hypothesis 3. In the survey that examines self-efficacy for group work, the experimental group who participated in AL-PNPE program will show a different mark compared to the control group. Hypothesis 4. In the survey that examines team efficacy, the experimental group who participated in AL-PNPE program will show a different mark compared to the control group.

\section{Research method}

\subsection{Research design}

This study was a quasi-experimental study with a non-equivalent control group pretestposttest design whose purpose is to develop AL-PNPE program and verify its influence on nursing students' ability to solve problems, ability to perform nursing skills, self-efficacy for group work as well as team efficacy.

\subsection{Participants}

The participants of the study were 4th grade senior students of $\mathrm{C}$ and $\mathrm{CH}$ colleague situated in $\mathrm{G}$ metropolitan city in South Korea. In the course of the study the students of C colleague were assorted as experimental group, and those of $\mathrm{CH}$ colleague were assorted as control group. The number of study participants was calculated using $G^{*}$ Power 3.1.9.2 program. An independent samples $t$ - test process, calculated with figures of significance level $(\alpha)$ of 0.05 , statistical power $(1-\beta)$ of 0.90 , effect size (d) of 0.80 , and group size 2 , showed that the minimum number of participants for each group was 34.3 of the 45 experimental group participants withdrew from clinical practice due to hospitalization, temporary absence from school or the wish to withdraw, and 5 of the 45-control group were excluded for a number of reasons including omitted questionnaire responses - eventually 82 people participated in this study.

\subsection{Measurements}

The study participants were classified by their general characteristic; gender, age, religion, level of satisfaction studying nursing and academic achievement. Problem solving ability stand for the ability to clarify the problem, analyze its cause, come up with an alternative solution, and manage the plans to carry out the solution and to evaluate its consequences, all in order to 
solve the problem at hand [18]. To measure this ability, a college student/adult-targeted questionnaire developed in a study on the development of life-skills by Lee, Jang, Lee and Park [18] for KEDI (Korean Educational Development Institute); the questionnaire was used with permission, citing the source and bibliography. The competency in nursing skills was directly evaluated by peer nursing students, and the standard for measurement was a checklist that included 21 items 'gastrointestinal tract' and 23 items 'intramuscular injection' developed by the Korea Institute of Accreditation Board of Nursing Education (KABONE) [14]. The Selfefficacy for group work means a belief in one's ability to successfully participate in collaborative learning-activities to carry out group works [19], and in this study, it should be interpreted as whether the student believes that he/she can contribute to cooperative work. The measuring tool used was approved by Kim [20], who translated and modified the 'self-efficacy for group work measure' developed by Alavi and McCormick [21]. 19 questions were answered with a five-point scale; the higher the score, the better the cooperative self-efficacy. The internal reliability of the measurement tools by Alavi and McCormick [21] at the time of development was .95; the Cronbach's alpha was .93 in Kim [20], and in this study, the pre-test reliability was .95 , and in the post-test, .94 . Team efficiency is a belief on a collaborative level that enables teams achieve the entrusted tasks, a shared belief among the team constituents in the ability of the group [22]; this means that each individual believes in the team's ability to successfully perform a given learning task with the team members [6]. In this study, the team efficacy tool of Kwon [23], which used the collective efficacy tool of Marshall [22], was used with modification and supplementation. 8 questions were answered with a five-point scale; a higher score meant a better team efficacy. In the study of Kwon [23], the reliability of the tool was .97 , the pre-test reliability of Cronbach's alpha was .95 , and in the post-test, .96 .

\subsection{Data collection}

The data were collected from March 4, 2019 to June 14, 2019. The preliminary test evaluated problem solving abilities, competency in nursing skills, self-efficacy for group work, and team efficacy. The survey was conducted to the experimental group during orientation for pediatric nursing practice education; the survey took about 20 minutes. The post test, which included identical questions to the pretest, was conducted 2 weeks after the end of the program to both the experimental group and the control group.

\subsection{Data analysis}

The collected data were analyzed using the SPSS Statistics 22.0 program. The general characteristics of the participants of the two groups were analyzed with numbers and percentages, and the data regarding general characteristics and dependent variables of the two groups - verified with a homogeneity test - were analyzed with $\chi^{2}$ - test and ANCOVA. And an independent t-test analyzed the calculated difference between the two group before and after the operation of AL-PNPE program.

\subsection{Ethical considerations}

For the protection of the participant's rights, the purpose of this study and its progress were explained. They were also explained that there were no side effects or hazards arising from the participation. The data collected were used only for research purposes and that personal confidentialities were guaranteed. In addition, the research participation was conducted after a 
written voluntary consent; each participant was fully explained about the benefits and losses of the research participation, privacy and confidentiality.

\section{Results}

\subsection{Homogeneity of General Characteristics, Dependent Variables}

The results of the homogeneity test for the general characteristics and pre-dependent variables of the experimental and control groups under this study showed that the general characteristics of the two groups did not differ statistically significantly and therefore that the two groups were homogeneous [Table. 1]. When it comes to AL-PNPE program, the pretest showed significant differences between two groups in problem solving abilities, competency in nursing skills, self-efficacy for group work, and team efficacy, resulting in unhomogeneity [Table. 2].

Table 1. Homogeneity test for measured between experimental and control groups $(\mathrm{N}=82)$

\begin{tabular}{|c|c|c|c|c|c|}
\hline \multicolumn{2}{|l|}{ Categories } & $\begin{array}{c}\text { Exp. }(n=42) \\
N(\%) \text { or } M \pm S D\end{array}$ & $\begin{array}{c}\text { Cont. }(\mathrm{n}=40) \\
\mathrm{N}(\%) \text { or } \mathrm{M} \pm \mathrm{SD}\end{array}$ & $\chi^{2}$ & $\mathrm{p}$ \\
\hline \multirow{2}{*}{ Gender } & Male & $5(11.9)$ & $3(07.5)$. & \multirow{2}{*}{0.47} & \multirow{2}{*}{0.47} \\
\hline & Female & $37(88.1)$ & $37(92.5)$ & & \\
\hline Age (yrs) & & $23.41 \pm 4.41$ & $24.02 \pm 5.02$ & 1.20 & .248 \\
\hline \multirow{2}{*}{ Religion } & Yes & $20(47.6)$ & $15(37.5)$ & \multirow{2}{*}{0.74} & \multirow{2}{*}{0.74} \\
\hline & No & $22(52.4)$ & $25(62.5)$ & & \\
\hline \multirow{3}{*}{$\begin{array}{l}\text { Satisfaction with } \\
\text { nursing science }\end{array}$} & High & $15(35.7)$ & $16(40.0)$ & \multirow{3}{*}{2.32} & \multirow{3}{*}{.107} \\
\hline & Middle & $25(59.5)$ & $23(57.5)$ & & \\
\hline & Low & $2(04.8)$ & $1(02.5)$ & & \\
\hline \multirow{3}{*}{ Learning achievement } & High & $8(19.0)$ & $6(15.0)$ & \multirow{3}{*}{0.03} & \multirow{3}{*}{.829} \\
\hline & Middle & $32(76.2)$ & $30(75.0)$ & & \\
\hline & Low & $2(04.8)$ & $4(10.0)$ & & \\
\hline
\end{tabular}

Table 2. Differences of the outcome variables between the two group $(\mathrm{N}=82)$

\begin{tabular}{|c|c|c|c|c|}
\hline Categories & $\begin{array}{c}\text { Exp. }(\mathrm{n}=42) \\
\mathrm{N}(\%) \text { or } \mathrm{M} \pm \mathrm{SD}\end{array}$ & $\begin{array}{c}\text { Cont. }(\mathrm{n}=40) \\
\mathrm{N}(\%) \text { or } \mathrm{M} \pm \mathrm{SD}\end{array}$ & $\mathrm{t}$ & $\mathrm{p}$ \\
\hline Problem solving abilities & $3.45 \pm 0.38$ & $3.42 \pm 0.33$ & 0.28 & .778 \\
\hline Competency in nursing skills & $92.19 \pm 0.26$ & $92.02 \pm 0.86$ & 1.20 & .248 \\
\hline Self-efficacy for group work & $3.62 \pm 0.58$ & $3.69 \pm 0.35$ & -0.80 & .423 \\
\hline Team efficacy & $3.89 \pm 0.62$ & $4.01 \pm 0.11$ & -0.24 & .679 \\
\hline
\end{tabular}

*Exp. $=$ Experimental; Cont. $=$ Control group 


\subsection{Effects of AL-PNPE program}

The first hypothesis, that the problem-solving skills of the experimental group attained through AL-PNPE program would be much higher than those in the control group, was supported by statistically significant differences between the experimental group and the control group $(\mathrm{t}=4.99, \mathrm{p}<.001)$. The second hypothesis, that the competency in nursing skills of the experimental group attained through AL-PNPE would be higher than the control group, was supported by statistically significant differences between the experimental group and the control group $(\mathrm{t}=3.99, \mathrm{p}<.001)$. The third hypothesis, that the self-efficacy for group work of the experimental group attained through AL-PNPE program would be much higher than those in the control group, was supported by statistically significant differences between the experimental group and the control group $(t=3.91, p<.001)$. Finally, the fourth hypothesis, that the team efficacy of the experimental group attained through AL-PNPE program would be much higher than those in the control group, were also supported by significant differences between the two groups $(\mathrm{t}=2.25, \mathrm{p}=.027)$ [Table 3].

Table 3. Effects of the AL-PNPE program between two groups $(\mathrm{N}=82)$

\begin{tabular}{|c|c|c|c|c|c|c|}
\hline Variables & Groups & $\begin{array}{l}\text { Pre-test } \\
\mathrm{M} \pm \mathrm{SD}\end{array}$ & $\begin{array}{c}\text { Post-test } \\
\mathrm{M} \pm \mathrm{SD}\end{array}$ & $\begin{array}{c}\text { Difference } \\
M \pm S D\end{array}$ & $\mathrm{t}$ & $\mathrm{p}$ \\
\hline \multirow{2}{*}{$\begin{array}{c}\text { Problem solving } \\
\text { abilities }\end{array}$} & Exp. $(n=42)$ & $3.45 \pm 0.38$ & $3.66 \pm 0.36$ & $0.22 \pm 0.43$ & \multirow{2}{*}{4.49} & \multirow{2}{*}{$<.001$} \\
\hline & Cont. $(n=40)$ & $3.42 \pm 0.33$ & $3.51 \pm 0.26$ & $0.09 \pm 0.34$ & & \\
\hline \multirow{2}{*}{$\begin{array}{l}\text { Competency in } \\
\text { nursing skills }\end{array}$} & Exp.(n=42) & $91.19 \pm 0.26$ & $98.40 \pm 0.51$ & $7.22 \pm 0.54$ & \multirow{2}{*}{3.99} & \multirow{2}{*}{$<.001$} \\
\hline & Cont. $(\mathrm{n}=40)$ & $92.02 \pm 0.86$ & $93.09 \pm 0.45$ & $1.07 \pm 0.44$ & & \\
\hline \multirow{2}{*}{$\begin{array}{l}\text { Self-efficacy for } \\
\text { group work }\end{array}$} & Exp. $(n=42)$ & $3.62 \pm 0.58$ & $3.92 \pm 0.52$ & $0.31 \pm 0.60$ & \multirow{2}{*}{3.91} & \multirow{2}{*}{$<.001$} \\
\hline & Cont. $(n=40)$ & $3.69 \pm 0.35$ & $3.78 \pm 0.37$ & $0.09 \pm 0.48$ & & \\
\hline \multirow{2}{*}{ Team efficacy } & Exp. $(n=42)$ & $3.89 \pm 0.62$ & $4.13 \pm 0.61$ & $0.39 \pm 0.53$ & \multirow{2}{*}{2.25} & \multirow{2}{*}{.027} \\
\hline & Cont. $(\mathrm{n}=40)$ & $4.01 \pm 0.89$ & $4.03 \pm 0.41$ & $0.16 \pm 0.37$ & & \\
\hline
\end{tabular}

*Exp. $=$ Experimental; Cont. $=$ Control group

\section{Conclusions}

This study aims to develop AL-PNPE program for nursing students and verify effects the program has on nursing students' abilities to solve problems and to perform nursing skills, as well as effects on cooperative self-efficacy and team efficacy. Through this study, we confirmed that applying AL-PNPE program to nursing students' practice course is effective in improving problem solving abilities, competency in nursing skills, self-efficacy for group work, and team efficacy. Results of this study confirm that action learning can help individuals think creatively and critically as they go through various problem-solving processes; help them learn and collaborate with each other; increase confidence in themselves as well as competence; and likely help them solve clinical problems in action while they are studying and training. To conclude, it is suggested that AL-PNPE program should be applied to the educational program of nursing college students. Repetitive researches on action learning based education programs for nursing college students are demanded, as is a cross-sectional research to verify the effects after providing direct action learning during pediatrics nursing clinical practice. 


\section{References}

[1] Korean Council for University College Education, Project Design Practice Training Course (2018-41), (2018)

[2] P. Blumberg, "Evaluating the evidence that problem-based learners are self-directed learners: A review of the Literature," In D. H. Evensen and C. E. Hmelo (Eds.), Problem based learning; A research prospective on learning interactions, NJ: Lawrence Erlbaum Associates, (2000)

[3] I. Cunningham, "The wisdom of strategic learning: The self-managed learning solution (2nd ed.)," London: Gower, (1999)

[4] K. W. Chang and Lee J. E., "An analysis of perceptions of learner-centered education by administrations, inservice teachers, and preservice teachers," Journal of Learner-Centered Curriculum and Instruction, vol.9, no.1, pp.315-339, (2009)

[5] K. W. Chang and S. I. Ko, “Action learning," Hakjisa: Seoul, (2014)

[6] G. Gardner, et al., "Nurse practitioner education: Research-based curriculum structure," Journal of Advanced Nursing, vol.47, no.2, pp.143-152, (2004)

[7] A. Marlow, et al., "Collaborative action learning: A professional development model for educational innovation in nursing," Nurse Education in Practice, vol.8, no.3, pp.184-189, (2008)

[8] D. Penney and B. Leggett, "Connecting initial teacher education and continuing professional learning through action research and action learning," Action learning: Research and Practice, vol.2, no.2, pp.153-169, (2005)

[9] Y. M. Kim, "Evaluation of design and operation of action learning based professionalism course for nursing students," [dissertation], Gwangju: Chonnam National University, (2012)

[10] W. J. Kim and Park J. H., "The effects of an action learning-based nursing ethics education on self-assertiveness and ethical values," Journal of Muscle Joints Health, (2017); vol.24, no.3, pp.179-186, http://dx.doi.org/10.5953/ JMJH.2017.24.3.179

[11] K. S. Jang and S. J. Park, "Effects of action learning approaches on learning outcomes in nursing management courses," Journal of Korean Academy of Nursing Administration, (2012), vol.18, no.4, pp.442-451, http://dx.doi.org/10. 11111/jkana.2012.18.4.442

[12] K. S. Jang, et al., "Effects of action learning based creative problem-solving course for nursing students," Journal of Korean Academy of Nursing Administration. (2014), vol.20, no.5, pp.587-598, http://dx.doi.org/ 10.11111/jkana.2014.20.5.587

[13] L. Yorks, et al., "Action learning; theoretical bases and varieties of practice,” in Action Learning: Successful Strategies for Individual, Team and Organizational Development, San Franscisco: Berrett-Koehler, (1999)

[14] Korean Accreditation Board of Nursing Education, "The accreditation nursing education: Core basic nursing skills protocol," [Internet], Seoul: Korean Accreditation Board of Nursing Education, (2017) [cited 2017 February 22]

[15] G. H. Kim and M. K. Park, "Comparative study on self-leadership, team efficacy, problem-solving process and task satisfaction of nursing students in response to clinical training," Journal of Korean Academy Nursing Education, vol.20, no.4, pp.482-490, (2014)

[16] M. R. Eom, et al., "Effects of teaching methods using standardized patients on nursing competence in subcutaneous injection, self-directed learning readiness, and problem-solving ability," Journal of Korean Academy Nursing, vol.40, no.2, pp.151-160, (2010)

[17] E. H. Chang and S. H. Park, "Effects of self-evaluation using smartphone recording on nursing students' competency in nursing skills, satisfaction, and learning motivations: Focusing on foley catheterization," Journal of Korean Academy Fundamental Nursing, (2017), vol.24, no.2, pp.118-127, http://dx.doi.org/10.7739/jkafn. 2017.24.2.118

[18] S. J. Lee, et al., "A study on the development of life-skills: Communication, problem-solving, and self-directed learning,” Seoul: Korean Educational Development Institute, Report No: RR 2003153, (2003)

[19] A. Bandura, "Self-efficacy: The exercise of control," New York: Freeman, (1997) 
[20] S. B. Alavi and J. MacCormick, "The roles of perceived task interdependence and group members' interdependence in the development of collective efficacy in university student group contexts," British Journal of Educational Psychology, vol.78, pp.375-393, (2008)

[21] S. Y. Kim, "The relationship between self-efficacy for group work, perceived usefulness, flow, perceived interaction, and learning outcomes in team project-based learning with closed-type SNS," [dissertation], Seoul: Ehwa Woman's University, (2016)

[22] L. C. Marshall, "The relationship between efficacy, teamwork, effort and patient satisfaction," [dissertation], The University of Southern California, (2003)

[23] E. M. Kwon, “The correlation among team efficacy, interpersonal understanding, proactivity in problem solving and team performance," [master's thesis], Seoul: Ehwa Womans University, (2010)

[24] K. S. Jang, et al., “An analysis of nurse managers' common fundamental competencies changes and responses to the application of the action learning," Journal of Korean Academy of Nursing Administration, vol.12, no.3, pp.424-433, (2006)

[25] Y. M. Kim and Y. H. Kim, "Development and evaluation of action learning in clinical practice of nursing management," The Journal of the Korea Contents Association, (2010), vol.10, no.6, pp.312-322

[26] Y. M. Kim, Evaluation of design and operation of action learning based nursing professionalism course of nursing students," [dissertation], Gwangju: Chonnam National University, (2012)

[27] K. Y. Im, "Self-efficacy in group investigation collaborative learning," Theory and practice of Education, vol.16, no.2, pp.19-36, (2011)

[28] K. Rajiah, "Technology enhanced collaborative learning in small group teaching sessions using padlet application: A pilot study," Research Journal of Pharmacy and Technology, vol.11, no.9, pp.3943-3946, (2018), Doi:10.5958/0974-360x.2018.00724.2

[29] M. S. Park, "A longitudinal study on the factors affecting team performance among college students: The development of team efficacy perspective," [master's thesis], Asan: Hoseo University, (2018) 